\title{
UCAPAN TERIMA KASIH
}

Ucapan terima kasih dan penghargaan disampaikan kepada para pakar yang telah diundang sebagai Mitra Bestari/Penelaah oleh Majalah IImiah Pengkajian Industri dalam Volume 11, No. 2, Tahun 2017. Berikut ini daftar nama pakar yang berpartisipasi :

\begin{tabular}{|l|l|}
\hline Nama & Alamat/Instansi \\
\hline $\begin{array}{l}\text { Dr, Ir. Eko Syamsudin, M.Sc. } \\
\text { (Specialist Avionics and Navigation) }\end{array}$ & $\begin{array}{l}\text { Pusat Teknologi Industri Keamanan dan } \\
\text { Pertahanan } \\
\text { Gedung Teknologi 2, PUSPIPTEK, Serpong }\end{array}$ \\
\hline $\begin{array}{l}\text { Agus Suhartono, H.Dr.Ing.Ir. } \\
\text { (Bid.Material) }\end{array}$ & $\begin{array}{l}\text { B2TKS, Kawasan Puspiptek, } \\
\text { Gedung 220 Kawasan PUSPIPTEK, Serpong, } \\
\text { Tangerang, Banten }\end{array}$ \\
\hline $\begin{array}{l}\text { Dr.Ir. Suryadi,MT. } \\
\text { (Bidang Mekanika dan Material) }\end{array}$ & $\begin{array}{l}\text { Pusat Teknologi Material } \\
\text { Gedung Pusat Teknologi Material (224), Lt.2 } \\
\text { Kawasan Puspiptek Serpong, }\end{array}$ \\
\hline $\begin{array}{l}\text { Prof. Dr. Ir. Buana Maruf,MSc } \\
\text { (Bidang Teknik Perkapalan) }\end{array}$ & $\begin{array}{l}\text { Pusat Teknologi Rekayasa Industri Maritim } \\
\text { Gedung Teknologi 2 Lt.3, Kawasan } \\
\text { PUSPIPTEK, Serpong, Tangerang, Banten }\end{array}$ \\
\hline $\begin{array}{l}\text { Dr. Ir. Amin Suhadi, M. Eng } \\
\text { (Bidang Mekanika dan Material) }\end{array}$ & $\begin{array}{l}\text { B2TKS, Kawasan Puspiptek, } \\
\text { Gedung 220 Kawasan PUSPIPTEK, Serpong, } \\
\text { Tangerang, Banten }\end{array}$ \\
\hline $\begin{array}{l}\text { Dr. Ir. Rizkon Fajar, } \\
\text { (Bid.Teknik Bahan Bakar dan Pembakaran) }\end{array}$ & $\begin{array}{l}\text { Pusat Teknologi Sistem dan Prasarana } \\
\text { Transportasi } \\
\text { Gedung Teknologi II (251), Lt.3 Kawasan } \\
\text { Puspiptek Serpong, }\end{array}$ \\
\hline
\end{tabular}




\section{SUSUNAN REDAKTUR PELAKSANA}

\section{Editor in Chief :}

Dr. Ir. Rizqon Fajar, M.Sc (Tek. Bahan Bakar dan Pembakaran) (PTSPT)

\section{Editors :}

Dr. Dipl.Ing. Mulyadi Sinung Harjono,MT (PTSPT-BPPT)

Ir. Endro Wahju Tjahjono, (PTSEIK-BPPT)

\section{Section Editors :}

Ihwan Haryono,ST, (BT2MP-BPPT)

Eka Febriyanti, ST. MT. (B2TKS-BPPT)

Mohamad Ivan Ajisaputro,ST, (PTSTP-BPPT)

\section{Copy Editors :}

Prasetyaning Diah Rizky Lestari,M.Si, (BT2MP-BPPT)

Dimas Bahtera Eskayudha,ST (PTSPT-BPPT)

Malinda Sabrina,S.Si (PTSPT-BPPT)

Hendrato, ST (PTSPT-BPPT)

Fitriyanto, ST, (PTIH-BPPT)

Siti Yubaidah, ST, MT, (BT2MP-BPPT)

\section{Layout Editors :}

Muhammad Maruf,MT, (BT2MP-BPPT)

Era Restu Finalis, ST,MT (PTSEIK-BPPT)

\section{Proofreaders :}

Eka Febriyanti, ST. MT. (B2TKS-BPPT)

Ihwan Haryono,ST, (BT2MP-BPPT)

\section{Reviewers :}

Dr. Maizirwan Mel, MSc. Bidang Bio Process Engineering IIUM Gombak-Kuala Lumpur

Dr. Ing.Ir,. Prof. Ir. Wimpie Agoeng N. Aspar, MSCE., Ph.D. Bidang Teknik Sipil BPPT

Dr.Ir. Eko Syamsudin, M. Sc. Bid. Teknik Mesin, Industri Hankam BPPT

Prof. Dr.Ir. Sulistijono, DEA Bidang Teknik Desain Material FTI-ITS

Dr, Ir. Myrna Ariati,MS Bidang Metalurgi dan Material, FT-UI

Dr. Ir. I Nyoman Jujur, M.Eng. Bidang Teknik Mesin BPPT

Prof.Dr.Ir. Buana Maruf, Bidang Tranportasi Perkapalan BPPT

Dr. Ir. Amin Suhadi, M. Eng Bidang Mesin dan Material BPPT

Dr. Ir. H. Agus Suhartono Bidang Material BPPT

Dr.Ir. Suryadi,MT, Bidang Mesin dan Material BPPT

Prof. Dr. Ir. Bambang Teguh P., Dipl. Ing. DEA. Bidang Mekanika Fluida, Konversi Energi BPPT

Dr. Ir. Cuk Supriyadi Ali Nandar, M.Eng. Bidang Teknologi Sistem Stabilitas Ketenagaan dan

Kendali BPPT

Dr. Hari Setiapraja, M.Eng. Bidang Teknologi Industri dan Otomotif BPPT

Ir. Djoko W. Karmiadji, MSME., Ph.D., Bidang Konstruksi Beton, Teknik Sipil BPPT 


\section{Pengantar}

Majalah Pengkajian Industri Volume 11 No. 2 Agustus 2017 merupakan edisi dengan topik Industri Teknologi Transportasi. Teknologi transportasi selama ini terus dikembangkan baik berupa sarana maupun prasarana, karena adanya peningkatan tuntutan kebutuhan akan pemindahan manusia dan barang yang aman, nyaman dan cepat. Banyak penelitian dan kajian yang dilakukan oleh berbagai pihak baik berupa lembaga maupun perorangan yang bertujuan untuk memenuhi tuntutan tersebut. Pada Majalah IImiah Pengkajian Industri edisi kali ini memuat beberapa penelitian dan kajian menarik mengenai industri transportasi terutama untuk kepentingan pertahanan nasional diantaranya adalah :. Simulasi Numerik Hidrodinamika Pada Desain Konfigurasi Wave Deflector Untuk Kendaraan Amfibi Beroda Ban, Kemampuan Strategis Pesawat Udara Nir Awak Bppt Untuk Dioperasikan Dari Kapal Perang serta Anoda Pb dan Gel Elektrolit Untuk Propulsi Kapal Selam

Pada terbitan ini juga ditampilkan topik yang terkait penelitian dan analisa yang terkait transportasi yaitu, Analisis Kekuatan Lentur Statis Dan Dinamis Bantalan Sintetis Untuk Jalan Kereta Api. Analisis Kegagalan Impeller Penyebab Kerusakan Pompa Air Kapal Laut. Analisis Kerusakan Radiator Sepeda Motor 150cc, Analisis Pembebanan Statik Pada Rangka Bogie Automatic People Mover System (Apms) Menggunakan Standar Uic-615 Dengan Finite Element. Dan Kajian Hidrodinamika Kapal Semikatamaran Untuk Transportasi Sungai

Semoga pembahasan pada terbitan ini bermanfaat bagi perkembangan industri transportasi sehingga mampu menjadi industri yang unggul dengan didukung oleh sumber daya yang produktif. Diharapkan juga informasi ini akan menjadi bagian dalam perkembangan penelitian dan kerekayasaan lebih lanjut.

Redaksi selalu berusaha melakukan perbaikan-perbaikan dalam rangka meningkatkan mutu Majalah Pengkajian Industri. Selanjutnya redaksi berencana menerbitkan Vol. 11 No. 3 bulan Desember 2017 dengan Topik "Industri Teknologi Hankam dan Material". Redaksi sangat mengharapkan adanya kritik dan saran yang sifatnya membangun. 


\section{Majalah Pengkajian Industri}

- Analisis Kegagalan Impeller Penyebab Kerusakan Pompa Air Kapal Laut. Impeller Failure Analysis Causes Of Sentrifugal Pump Damage From Ship Unit (Eka Febriyanti, Sutarjo, Khairul Anwar)

- Analisis Kekuatan Lentur Statis Dan Dinamis Bantalan Sintetis Untuk Jalan Kereta Api

Static And Dynamic Analysis Of Bending Strength Of Synthetic Sleepers For Railway (Puguh Triwinarno)

- Analisis Kerusakan Radiator Sepeda Motor 150cc Failure Analysis of $150 \mathrm{cc}$ Motor Cycle Radiator. (Amin Suhadi)

- Simulasi Numerik Hidrodinamika Pada Desain Konfigurasi Wave Deflector Untuk Kendaraan Amfibi Beroda Ban

Simulation Of Numerical Hydrodynamics In Wave Deflector Configuration Design For Equipment Amfibi Vehicles. (Abdul Aziz, Abid Paripurna Fuadi, Apid Rustandi)

- Kemampuan Strategis Pesawat Udara Nir Awak Bppt Untuk Dioperasikan Dari Kapal Perang.

The Strategic Flight Performance Of Bppt Uav For Supporting The Naval Operation. (Jemie Muliadi, Dewi H. Budiarti, Akhmad Rifai, Dyah Jatiningrum)

- Analisis Pembebanan Statik Pada Rangka Bogie Automatic People Mover System (Apms) Menggunakan Standar Uic-615 Dengan Finite Element. Analysis Of Static Loading On Bogie Frame Automatic People Mover System (Apms) Using Uic-615 Standard With Finite Element. (Setyo Margo Utomo, Jean Mario Valentino, Beny Halfina, Hendrato)

- Anoda Pb dan Gel Elektrolit Untuk Propulsi Kapal Selam Anoda Pb and Electrolit Gel forSubmarine Propution. (Hens Saputra, M. Rosjidi, Abdul Ghofar, Murbantan T., M. Ismail, Dorit B. Islami)

- Kajian Hidrodinamika Kapal Semikatamaran Untuk Transportasi Sungai. Study Of Semikatamaran Ship Hydrodynamics For River Transportation. (Luhut Tumpal Parulian Sinaga) 